\title{
Pregnancy and heart disease: risk and predictors of obstetric complications
}

\author{
Cicily T. J.*, Sherin Sams, Soniya C. Alphonse
}

Department of Obstetrics and Gynecology, Government Medical College, Kottayam, Kerala, India

Received: 13 April 2017

Accepted: 22 April 2017

*Correspondence:

Dr. Cicily T. J.,

E-mail: dr.cicilytj@gmail.com

Copyright: ( ) the author(s), publisher and licensee Medip Academy. This is an open-access article distributed under the terms of the Creative Commons Attribution Non-Commercial License, which permits unrestricted non-commercial use, distribution, and reproduction in any medium, provided the original work is properly cited.

\section{ABSTRACT}

Background: Although the disease is limited to only 0.5 to 1.0 percent of pregnant women, it remains an important cause of maternal morbidity and even mortality and has a significant effect on fetal outcome. Pregnancy and the peripartum period are associated with important cardiocirculatory changes that can lead to marked clinical deterioration in the woman with heart disease. Objectives of present study were to comprehend the impact of heart disease during pregnancy, to study the maternal and neonatal outcomes of pregnancies in women with heart disease, to identify predictors of pregnancy related complications in women with heart disease and to refine the risk stratification and to assess the individual risk of each pregnant woman with heart disease.

Methods: It is a perspective study carried out at College Department of Obstetrics and Gynaecology, Govt. Medical, Kottayam from January 2012 to March 2014.

Results: The outcomes of the pregnancies in 100 women who presented with heart disease and received their obstetrical care were evaluated. A maternal cardiac event, neonatal event, or both occurred in 37 completed pregnancies. A cardiac event complicated 8 completed pregnancies. It includes 2 maternal deaths, one on 9th postnatal day in women with hypertrophic obstructive cardiomyopathy and another in women with rheumatoid mitral stenosis who died of congestive cardiac failure. Most cardiac events (75\%) occurred in the antepartum period and were either heart failure or cardiac arrhythmia.

Conclusions: Strict prenatal care and early risk stratification during gestation are fundamental measures to improve the prognosis of pregnancy in women with heart disease.

Keywords: Heart diseases, Pregnancy complications, Pregnancy, Pregnancy outcome

\section{INTRODUCTION}

Maternal cardiac diseases complicate $1 \%$ of all pregnancies and are responsible for about $15 \%$ of all maternal deaths. The incidence of cardiac disease during pregnancy has remained stable for many years since the significant decrease in the occurrence of rheumatic heart disease in the last few decades has been compensated by a significant increase of pregnancy in women with congenital heart disease. In developed countries, survival of newborns affected by congenital heart disease is about $85 \%$ in many cases as a result of complex surgical procedures performed in the first few years of life. ${ }^{1}$ As a result the cardiologists and obstetricians are today facing an increasingly large group of pregnant women with surgically corrected congenital abnormalities. As these women contemplate pregnancy, they seek counseling regarding maternal and fetal outcome. The obstetrician should have adequate information about cardiac diseases during pregnancy so that he/she can function effectively as a member of the team that will be taking care of the patient. Hemodynamics are altered during pregnancy in different stages: antenatal during labor and delivery, during caesarean section and during postpartum period. Hemodynamic adaptation to pregnancy persists postpartum and gradually returns to prepregnancy values 
within 12 to 24 weeks after delivery. ${ }^{2}$ Siu and Associates (2001) expanded on the NYHA Classification and developed a scoring system for predicting cardiac complications during pregnancy which includes: ${ }^{1}$

- Prior heart failure, transient ischemic attack, arrhythmia or stroke.

- Baseline NYHA class III or greater or cyanosis.

- Left sided heart obstruction defined as mitral valve area less than $2 \mathrm{~cm}^{2}$, aortic valve area below $1.5 \mathrm{~cm}^{2}$, or peak left ventricular outflow gradient above 30 mm mercury by echocardiography.

- Ejection fraction less than 40 percent.

\section{Risks for maternal mortality caused by various types Heart Diseases $^{3,4}$}

\section{Group I Minimal Risk Mortality 0-1\%}

- Atrial Septal Defect

- Ventricular Septal Defect

- Patent Ductus Arteriosus

- Pulmonic or Tricuspid Disease

- Fallot Tetrology Corrected

- Bioprosthetic Valve

- Mitral Stenosis NYHA Class I and II.

Group II Moderate Risk Mortality 5-15\%

$2 \mathrm{~A}$

- Mitral Stenosis NYHA Class II and IV

- Aortic Stenosis

- Aortic Coarctation without valvular involvement

- Fallot Tetrology Uncorrected

- Previous Myocardial infarction

- Marfan Syndrome; Normal Aorta

$2 \mathrm{~B}$

- Mitral Steams with Atrial Fibrillation

- Artificial valve

\section{Group III Major Risk Mortality 25 - $50 \%$}

- Pulmonary Hypertension

- Aortic Coarctation with valvular involvement

- Marfan Syndrome with aortic involvement.

Discussions about future pregnancies, family planning, and contraception should begin in adolescence to prevent accidental and potentially dangerous pregnancies in women with congenital heart disease. The impact of heart disease on childbearing potential needs to be explained clearly and sympathetically. Counselling has to address how' pregnancy may affect not just the mother but also the fetus and the rest of the family. This allows women to make an informed choice whether they wish to accept the risks associated with pregnancy. The counselling should ideally be provided in a joint clinic by an obstetrician with expertise in heart disease and a cardiologist with special training in adult congenital heart disease. ${ }^{5}$

Pregnancy in women with congenital heart disease, maternal and fetal outcome is determined by the nature of the disease, surgical repair, presence and severity of cyanosis, increased pulmonary vascular resistance, maternal functional capacity, myocardial dysfunction, left ventricular obstruction, and history of arrhythmias or other prior cardiac events. Unfavourable outcome, including development of congestive heart failure, arrhythmias, infective endocarditis, thromboembolism and hypertension, is commonly seen in patients with impaired functional status and those with cyanosis. Fetal wastage was reported in $45 \%$ of cyanotic mothers compared with 20 percent in acyanotic mothers with congenital heart disease. Low birth weight for gestational age and prematurity are common in cyanotic mothers and correlate with maternal hemoglobin and hematocrit values. Risk of congenital heart disease is increased for the offspring of mothers with congenital heart disease with a reported incidence of 4 to 8 percent. In addition, there are a greater number of noncardiac congenital malformations, as well as mental and physical impairments in children born to mothers with congenital heart disease. ${ }^{6}$

Patients with chronic rheumatic valvular disease should be managed individually according to the site and severity of the lesion. However, certain general guidelines apply to the care of all patients. These include restriction of physical activity in symptomatic patients to reduce cardiovascular load and prevent hemodynamic and symptomatic worsening and prophylactic antibiotic treatment to prevent streptococcal infection and recurrence. $^{1,2}$ Hemodynamic monitoring is strongly recommended from the onset of labor to approximately 24 hours postpartum in any patient who experiences symptoms of heart failure during pregnancy and for those with severe valvular disease, left ventricular dysfunction, or pulmonary hypertension. ${ }^{4}$ Mitral stenosis is the most commonly encountered valvular lesion in pregnancy and is caused in almost all cases by rheumatic heart disease. ${ }^{7,8}$ Although rheumatic MS is often accompanied by some degree of mitral regurgitation (MR), pregnancy related hemodynamic and symptomatic problems are predominantly due to valve stenosis., ${ }^{7,9}$

Maternal outcome was favourable in patients with mild MS and comparable to their control; in contrast, there was a significantly higher incidence of maternal morbidity in women with moderate and severe MS, including the development of heart failure, arrhythmias (atrial fibrillation or supraventricular tachycardia), the need to start and/or increase a dose of cardiac medications, and the need for hospitalizations. Surgical mitral valve repair or replacement should be considered during pregnancy only in cases with severe MS who are 
refractory to optimal medical therapy and are not suitable candidates for Percutaneous Mitral Balloon Valvuloplasty (PMBV) or in cases where close follow-up during pregnancy is not possible. ${ }^{7,10}$

Hemodynamic monitoring during labour and delivery with a pulmonary artery catheter is recommended in all patients with moderate and severe MS. ${ }^{11}$ Optimization of left atrial pressure before delivery may be needed and can be achieved by diuresis and reduction of heart rate with beta-blockers. ${ }^{12}$ Increased venous return in the early puerperium may result in a marked increase in left atrial and pulmonary pressure and can lead to the development of pulmonary edema. For this reason, hemodynamic monitoring should continue for 12 to 24 hour after the delivery. The use of tocolytic agents with beta-mimetic effect is contraindicated in patients with MS because of their strong chronotropic effect, and the use of magnesium sulfate, which has negligible hemodynamic effect, is preferred. ${ }^{2}$

Mitral regurgitation is well tolerated even if severe. Asymptomatic patients do not require therapy during pregnancy, and the treatment of patients with left ventricular dysfunction who develop hemodynamic abnormalities and symptoms of heart failure can include the use of diuretics and digoxin. ${ }^{2,13}$

The prevalence of mitral valve prolapse in the general population has been found to be $2.4 \%$ and is reported in approximately $1.2 \%$ of pregnant women. Because of high incidence of systolic functional murmurs and wide splitting of the first heart sound during pregnancy, mitral valve prolapse may be falsely diagnosed and needs to be confirmed by echocardiographic criteria. ${ }^{6}$

Peripartum cardiomyopathy is a form of dilated cardiomyopathy with left ventricular systolic dysfunction that results in signs and symptoms of heart failure. The incidence of peripartum cardiomyopathy is greater in multiparous women and in those with preeclampsia and twin pregnancies, as well as in women older than 30 years of age. The clinical course of peripartum cardiomyopathy varies, with 50 to 60 percent of patients showing complete or near-complete recovery of clinical status and cardiac function, usually within the first 6 months postpartum; the rest of the patients demonstrate either further clinical deterioration, leading to cardiac transplantation or early death, or persistent left ventricular dysfunction and chronic heart failure. ${ }^{6,14}$

Primary pulmonary hypertension is one of the few cardiovascular conditions in which pregnancy can be associated with a high maternal mortality of 30 to 40 percent. In addition to high maternal risk, primary pulmonary hypertension is associated with poor fetal outcome with high incidence of fetal loss, prematurity and fetal growth retardation. ${ }^{15}$ Because of the potential deleterious effect of pregnancy on both mothers with primary pulmonary hypertension and their fetuses, pregnancy should be avoided in these patients and tubal ligation should be recommended. ${ }^{16}$ Early abortion is indicated in patients with primary pulmonary hypertension who become pregnant. If the patient elects to continue the pregnancy, physical exertion should be restricted to reduce the circulatory load. ${ }^{17}$

In patients with new-generation mechanical prosthetic valves the use of adjusted-dose heparin either throughout pregnancy or during the first trimester and after the $35^{\text {th }}$ to $36^{\text {th }}$ week of gestation is safe. ${ }^{18}$ The objectives of present study were to comprehend the impact of heart disease during pregnancy, to study the maternal and neonatal outcomes of pregnancies in women with heart disease, to identify predictors of pregnancy related complications in women with heart disease and to refine the risk stratification and to assess the individual risk of each pregnant woman with heart disease.

\section{METHODS}

This is a prospective study performed in the Department of Obstetrics and Gynaecology, Government Medical College, Kottayam during the period January 2012 to March 2014 after approval from the ethical committee Government Medical College, Kottayam. Proper informed consent was obtained from all the patients after explaining the benefits of the study.

Pregnant women who presented with heart disease and received their received their obstetrical care in Obstetrics and Gynaecology Department, Medical College, Kottayam.

\section{Inclusion criteria}

- Pregnant women with heart disease of congenital or acquired in origin.

\section{Exclusion criteria}

- Patients with isolated mitral valve prolapse

- Women with heart disease who underwent therapeutic abortions.

The outcomes of pregnancies in 100 women with heart disease who received their obstetrical care at Medical College Hospital, Kottayam from January 2012 to March 2014 were evaluated. Heart disease in this group was congenital or acquired in origin. Patients with isolated mitral valve prolapse were excluded because this condition is not associated with an increased rate of pregnancy-related complications. Also excluded were 13 women with heart disease who underwent therapeutic abortions. All pregnant women with heart disease receiving care in this hospital undergo standardized cardiac and obstetrical evaluations during their pregnancy. Their newborns were examined by a paediatrician before hospital discharge. Outcomes of newborns who were subsequently transferred to The 
Institute of Child Health, Kottayam for ongoing care were determined from the health records of that institution. Definitions of predictors and outcomes were determined by consensus between a cardiologist and obstetrician before data collection. Data were obtained from independent review of health and clinic records. Baseline data were collected before review of outcomes and included: maternal age, gestational age at 1st antenatal visit, New York Heart Association (NYHA) functional class at first antenatal visit, parity status, prior cardiac events (heart failure, transient ischemic attack, or stroke before present pregnancy), cardiac medications and heparin administered during pregnancy, prior cardiac surgical repair, evidence of central cyanosis, and nature of the underlying cardiac lesion.

Adverse events occurring during the antepartum, peripartum, and postpartum periods (before hospital discharge) were recorded. Maternal cardiac outcomes were defined as new-onset heart failure, symptomatic tachyarrhythmia or bradyarrhythmia, stroke or transient ischemic attack of cardiac origin, or cardiac death. Neonatal outcomes were defined as prematurity, smallfor-gestational-age birth weight (birth weight <10th percentile for gestational age), respiratory distress syndrome, neonatal death, or stillbirth.

Statistical analyses were performed for cardiac, neonatal, and secondary outcomes separately. Potential predictors of adverse outcomes in pregnancies not ending in miscarriage were examined with $\mathrm{X} 2$ test. Potential predictors included baseline NYHA functional class, prior corrective surgery, prior cardiac events, and nature of underlying cardiac lesion. In view of the wide spectrum of cardiac lesions that were present as well as the presence of multiple types of lesions in a single patient, the mother's cardiac lesion in each pregnancy was classified as present or absent in each of the following pathophysiological categories: left heart obstruction, right heart. obstruction, left heart regurgitation, right heart regurgitation. The presence of obstruction, regurgitation, and left ventricular systolic dysfunction was defined by validated trans-thoracic echocardiographic (echo) indices obtained during the ante partum period. Valve areas used to define left heart obstruction were set at a level that could be hemodynamically significant in the presence of increased cardiac output in pregnancy. When ante partum echo was not performed, echo data within the preceding 2 years were used unless the patient had experienced a change in clinical status or undergone intervention.

\section{Statistical analysis}

Age was expressed as mean $\pm \mathrm{SD}$ and qualitative data were expressed as number and percentages were given in parentheses. The observed differences in mean ages were evaluated using $t$ test. The differences in qualitative data were evaluated using Chi square test. When the cells in tables contain very small values, Fishers Exact test was used to test the difference. In all cases statistical significance was fixed at $5 \%$ level.

\section{RESULTS}

A total of 100 cases during the study period were included. The average age of the women was $26 \pm 2.5$ years. Cardiac events were present in $8 \%$ of the subjects and neonatal events were present in $35 \%$ subjects.

Table 1: Age and parity distribution and neonatal events.

\begin{tabular}{|c|c|c|c|c|c|c|c|c|}
\hline & $\begin{array}{l}\text { Cardiac events } \\
\text { present }\end{array}$ & $\begin{array}{l}\text { Cardiac } \\
\text { events absent }\end{array}$ & Statistic & p value & $\begin{array}{l}\text { Neonatal events } \\
\text { present }\end{array}$ & $\begin{array}{l}\text { Neonatal } \\
\text { events absent }\end{array}$ & Statistic & p value \\
\hline Age & $27.4+6.7$ & $26.6+5.3$ & 0.398 & $p>0.05$ & $27.5+4.4$ & $26.1+4.2$ & 1.56 & $\mathrm{p}>0.05$ \\
\hline \multicolumn{9}{|l|}{ Parity } \\
\hline Primi & $2(3.9)$ & $49(96.1)$ & 2.35 & $\mathrm{p}>0.05$ & $15(29.4)$ & $36(70.6)$ & 1.43 & $\mathrm{p}>0.05$ \\
\hline Multi & $6(12.2)$ & $43(87.8)$ & & & $20(40.8)$ & $29(59.2)$ & & \\
\hline
\end{tabular}

Table 2: NYHA class and cardiac and neonatal events

\begin{tabular}{|c|c|c|c|c|c|c|c|c|}
\hline $\begin{array}{l}\text { NYHA } \\
\text { classification }\end{array}$ & $\begin{array}{l}\text { Cardiac } \\
\text { events } \\
\text { present }\end{array}$ & $\begin{array}{l}\text { Cardiac } \\
\text { events absent }\end{array}$ & Statistic & $p$ value & $\begin{array}{l}\text { Neonatal } \\
\text { events } \\
\text { present }\end{array}$ & $\begin{array}{l}\text { Neonatal } \\
\text { events } \\
\text { absent }\end{array}$ & Statistic & p value \\
\hline Class 1 & 0 & $61(100.0)$ & 51.8 & $\mathrm{p}<0.001$ & $13(21.3)$ & 48 (78.7) & 13.6 & $\mathrm{p}<0.001$ \\
\hline Class 2 & 4 (11.4) & $31(88.6)$ & & & $19(54.3)$ & $16(45.7)$ & & \\
\hline Class 3 & $4(100.0)$ & 0 & & & $3(75.0)$ & $1(25.0)$ & & \\
\hline
\end{tabular}

The mean age was 26 years; the youngest was 18 and oldest 39 years. Most of the patients were nulliparous or para-1. There were no grand multiparous in the study group. There is no statistically significant association between maternal age, parity and cardiac or neonatal events $(\mathrm{p}>.05)$. 
Table 3: Type of lesion and cardiac and neonatal events.

\begin{tabular}{|c|c|c|c|c|c|c|c|c|}
\hline $\begin{array}{l}\text { Type of } \\
\text { lesion }\end{array}$ & $\begin{array}{l}\text { Cardiac } \\
\text { events } \\
\text { present }\end{array}$ & $\begin{array}{l}\text { Cardiac } \\
\text { events } \\
\text { absent }\end{array}$ & Statistic & p value & $\begin{array}{l}\text { Neonatal } \\
\text { events } \\
\text { present }\end{array}$ & $\begin{array}{l}\text { Neonatal } \\
\text { events absent }\end{array}$ & Statistic & $\begin{array}{l}\mathrm{p} \\
\text { value }\end{array}$ \\
\hline Congenital & $2(4.2)$ & $46(95.8)$ & 1.84 & $\mathrm{p}>0.05$ & $14(29.2)$ & $34(70.8)$ & 1.38 & $\mathrm{p}>0.05$ \\
\hline Acquired & $6(11.5)$ & $46(88.5)$ & & & $21(40.4)$ & $31(59.6)$ & & \\
\hline
\end{tabular}

Table 4: Twin gestation and cardiac and neonatal events.

\begin{tabular}{|c|c|c|c|c|c|c|c|c|}
\hline $\begin{array}{l}\text { Twin } \\
\text { gestation }\end{array}$ & $\begin{array}{l}\text { Cardiac } \\
\text { events } \\
\text { present }\end{array}$ & $\begin{array}{l}\text { Cardiac } \\
\text { events } \\
\text { absent }\end{array}$ & statistic & p value & $\begin{array}{l}\text { Neonatal } \\
\text { events } \\
\text { present }\end{array}$ & $\begin{array}{l}\text { Neonatal } \\
\text { events } \\
\text { absent }\end{array}$ & Statistic & p value \\
\hline Present & $2(100.0)$ & 0 & & $0.006 *$ & $2(100.0)$ & 0 & & $0.12 *$ \\
\hline Absent & $6(6.1)$ & 92 (93.9) & & & 33 (33.7) & $65(66.3)$ & & \\
\hline
\end{tabular}

Table 5: Type of obstruction and outcome and cardiac and neonatal events.

\begin{tabular}{|c|c|c|c|c|c|c|c|c|}
\hline $\begin{array}{l}\text { Type of obstruction and } \\
\text { outcome }\end{array}$ & $\begin{array}{l}\text { Cardiac } \\
\text { events } \\
\text { present }\end{array}$ & $\begin{array}{l}\text { Cardiac } \\
\text { events } \\
\text { absent }\end{array}$ & Statistic & p value & $\begin{array}{l}\text { Neonata } \\
\text { l events } \\
\text { present }\end{array}$ & $\begin{array}{l}\text { Neonata } \\
\text { l events } \\
\text { absent }\end{array}$ & Statistic & p value \\
\hline \multicolumn{9}{|l|}{ Right heart obstruction } \\
\hline Present & 0 & $3(100.0)$ & & $1.000 *$ & $1(33.3)$ & $2(66.7)$ & & $1.000 *$ \\
\hline Absent & $8(8.2)$ & $89(91.8)$ & & & $34(35.1)$ & $63(64.9)$ & & \\
\hline \multicolumn{9}{|l|}{ Right heart regurgitation } \\
\hline Present & $1(25.0)$ & $3(75.0)$ & & $0.287 *$ & $1(25.0)$ & $3(75.0)$ & & $1.000 *$ \\
\hline Absent & $7(7.3)$ & $89(92.7)$ & & & $34(35.4)$ & $62(64.6)$ & & \\
\hline \multicolumn{9}{|l|}{ Left heart obstruction } \\
\hline Present & $5(17.9)$ & $23(82.1)$ & 5.13 & $\mathrm{p}<0.05$ & $14(50.0)$ & $14(50.0)$ & 3.84 & $\mathrm{p}<0.05$ \\
\hline Absent & $3(4.2)$ & $69(95.8)$ & & & $21(29.2)$ & $51(70.8)$ & & \\
\hline \multicolumn{9}{|l|}{ Left heart regurgitation } \\
\hline Present & $3(13.0)$ & $20(87.0)$ & 1.03 & $\mathrm{p}>0.05$ & $9(39.1)$ & $14(60.9)$ & 0.224 & $\mathrm{p}>0.05$ \\
\hline Absent & $5(6.5)$ & $72(63.5)$ & & & $26(33.8)$ & $51(66.2)$ & & \\
\hline
\end{tabular}

Table 6: Surgical and medical management and cardiac and neonatal events.

\begin{tabular}{|c|c|c|c|c|c|c|c|c|}
\hline $\begin{array}{l}\text { Surgical and medical } \\
\text { management }\end{array}$ & $\begin{array}{l}\text { Cardiac } \\
\text { events } \\
\text { present }\end{array}$ & $\begin{array}{l}\text { Cardiac } \\
\text { events } \\
\text { absent }\end{array}$ & Statistic & p value & $\begin{array}{l}\text { Neonatal } \\
\text { events } \\
\text { present }\end{array}$ & $\begin{array}{l}\text { Neonatal } \\
\text { events } \\
\text { absent }\end{array}$ & Statistic & p value \\
\hline \multicolumn{9}{|c|}{ Prior surgical correction } \\
\hline Present & $3(13.0)$ & $20(87.0)$ & 1.03 & $\mathrm{p}>0.05$ & $9(39.1)$ & $14(60.9)$ & 0.224 & $\mathrm{p}>0.05$ \\
\hline Absent & $5(6.5)$ & $72(93.5)$ & & & $26(33.8)$ & $51(66.2)$ & & \\
\hline \multicolumn{9}{|l|}{ Prior cardiac events } \\
\hline Present & $4(44.4)$ & $5(55.6)$ & 17.8 & $\mathrm{p}<0.001$ & $8(88.9)$ & $1(11.1)$ & 12.6 & $\mathrm{p}<0.001$ \\
\hline Absent & $4(4.4)$ & $87(95.6)$ & & & $27(29.7)$ & $64(70.3)$ & & \\
\hline \multicolumn{9}{|l|}{ Cardiac medication } \\
\hline Present & $7(33.3)$ & $14(66.7)$ & 23.7 & $\mathrm{p}<0.001$ & $13(61.9)$ & $8(38.1)$ & 8.4 & $\mathrm{P}<0.001$ \\
\hline Absent & $1(1.3)$ & $78(98.7)$ & & & $22(27.8)$ & $57(72.2)$ & & \\
\hline
\end{tabular}

Most of the cases were class 1 or class 2. No patient in study group had class 4 heart disease. All the cases with class 3 heart disease were complicated by a cardiac event. NYHA class is a significant predictor of both cardiac events as well as neonatal events $(\mathrm{p}<.001)$.

Aetiological type of heart lesion was not a significant predictor of cardiac or neonatal events ( $p>.05)$.
Twin gestation was a significant predictor of cardiac events but not neonatal events.

Right heart obstruction and regurgitation and left heart regurgitation was not a significant predictor of maternal cardiac or neonatal events ( $p$ value 1.000 and 0.287 and $\mathrm{p}>0.05$ respectively. Right heart obstruction was a significant predictor of both maternal cardiac and neonatal events $(\mathrm{p}<0.05)$. 
Prior surgical correction was not a significant predictor of maternal cardiac or neonatal events $(p>0.05)$ whereas Prior cardiac events was a significant predictor of both maternal cardiac and neonatal events $(\mathrm{p}<0.001)$.

The requirement of cardiac medications during pregnancy was a significant predictor of both maternal cardiac and neonatal events $(\mathrm{p}<0.001)$.

\section{DISCUSSION}

The study provides a contemporary assessment of maternal and neonatal risk associated with pregnancy in women with heart disease who are receiving comprehensive prenatal care.

The cardiac event rate in the present study $(8 \%)$ is lower than that reported in previous studies. In a prospective multicenter study of pregnancy outcomes in women with heart disease, Siu et al reported a $13 \%$ incidence of primary cardiac events. This lower event rate may be explained in part by differences in study populations. As in the present study, the most common cardiac complications have consistently been congestive heart failure. Most cardiac events $(75 \%)$ occurred in the antepartum period and the results are comparable to $82 \%$ obtained by Siu S C et al. ${ }^{19}$ Neonatal complications occurred in $31 \%$ of pregnancies, comparable to the $27.8 \%$ reported by Khairy $\mathrm{P}$ et al. ${ }^{20}$ However, the high maternal mortality rate of $2 \%$ and fetal/neonatal mortality rate of $4 \%$ is not comparable with western studies. The low maternal and neonatal mortality observed in those studies may be due to greater vigilance in the care of pregnant women with heart disease or the avoidance of pregnancy by women in higher-risk groups.

The rate of preterm labor $(7 \%)$, respiratory distress syndrome (10\%) and low APGAR scores at birth (6\%) are comparable to previous studies by Khairy $\mathrm{P}$ et al. ${ }^{20}$ The high rate of small for gestational age fetuses (31\%) is not comparable with western studies probably due to difference in the ethnic group studied and hence the difference in birth weights.

Poor NYHA class, left heart obstruction, prior arrhythmia, and prior heart failure/stroke have been previously identified as risk factors for maternal cardiac events. The present study extends the results of previous studies by quantifying these risks prospectively in the population group studied. The present study also quantified the association of left heart obstruction and history of prior cardiac events with the risk of maternal cardiac complications during pregnancy. The association between left heart obstruction to cardiac events is probably mediated by the changes in cardiac output, heart rate, and systemic vascular resistance during pregnancy.

Poor NYHA class and maternal left heart obstruction was predictive of neonatal events in prior studies and in the present study. The predictive role of maternal left heart obstruction on neonatal outcome identified in this study may be mediated by inadequate placental perfusion, which then results in fetal growth retardation, fetal death or premature labor. Indeed, fetal cardiac contractility and output are adversely affected by hypoxic academia resulting from uteroplacental insufficiency.

The requirement of cardiac medications during pregnancy correlated well with poor functional class and was a significant predictor of maternal cardiac events and neonatal events.

Maternal age, panty, etiological type of lesion, right heart regurgitation, right heart obstruction and left heart regurgitation were not significant predictors of maternal cardiac events or neonatal events, The results are comparable to the observations by Siu S C et al from Canada. ${ }^{19}$

In contrast to previous study by Siu S C et al, the present study showed a strong predictive role for multiple gestation in the development of maternal cardiac complications ( $\mathrm{p}$ 0.00). ${ }^{19}$ Multiple pregnancies are characterized by marked variations in stroke volume and cardiac output during the antepartum period and at the time of labor and after delivery, as compared to singleton pregnancies. This could lead to maternal cardiac decompensation and increased rate of complications.

However, the current study failed to substantiate the previously reported predictive role of cyanosis and pulmonary artery hypertension on cardiac and neonatal outcome due to the lack of cases. There were no women with cyanosis or Eisenmenger syndrome in this study, probably because the results of prior studies dissuaded affected women from childbearing.

By combining cardiac lesions with similar hemodynamic bases into a single category, this strategy maximized the power to identify independent predictors. However, some categories may not be predictive of complications because of small numbers. A larger patient sample may allow the identification of additional risk factors.

\section{CONCLUSION}

Pregnancy in women with heart disease is still associated with considerable morbidity and mortality rates, which strongly correlate to maternal underlying disease. Maternal cardiac complications occurred in $8 \%$ of pregnancies in women with heart disease and the most common complication was congestive cardiac failure.

Neonatal complications occurred in $35 \%$ of pregnancies in women with heart disease and the most common complication was small for gestational age fetus.

The predictors of maternal complications were poor functional class, left heart obstruction, prior cardiac events, twin gestation and the requirement of cardiac 
medications during pregnancy. The predictors of neonatal complications included poor maternal functional class, left heart obstruction, prior cardiac events and the requirement of cardiac medications during pregnancy.

Maternal age, parity and the etiological type of lesion were not significant predictors of maternal cardiac or neonatal events. Strict prenatal care and early risk stratification during gestation are fundamental measures to improve the prognosis of pregnancy in women with heart disease.

\section{ACKNOWLEDGMENTS}

Authors are extremely thankful to Dr. Raju George, Professor and Head of Department of Cardiology for his sincere guidance, immense help and criticism which did a lot in making this study a reality. Authors are also thanked all the staff members and post graduate trainees of Department of Obstetrics and Gynaecology, Cardiology and Paediatrics for their help and suggestions. Author express their sincere thanks to all patients for their immense cooperation to complete the study. Above all Authors are grateful to the God Almighty for his blessings that have led to the completion of this study.

\section{Funding: No funding sources}

Conflict of interest: None declared

Ethical approval: The study was approved by the Institutional Ethics Committee

\section{REFERENCES}

1. Cunningham, F Gary, et al. Williams obstetrics $-22^{\text {nd }}$ Edition. USA: Mc Graw-Hill, 2005. ISBN: 0-07141315-4.

2. Uri E, Norbert G. Cardiac problems in pregnancy: diagnosis and management of maternal and fetal heart disease. New York:Wiley-Liss, 1998. ISBN 0471-16358-9.

3. ACOG technical bulletin. Cardiac disease in pregnancy. Technical Bulletin No 168, June 1992. Int J Gynecol Obstet. 1993;41(3):298-306.

4. Cleveland Clinic: Center for continuing education. The Cleveland Clinic Foundation. [Online] 2014. http://www.clevelandclinicmeded.com/medicalpubs/ diseasemanagement/cardiology/pregnancy-and-heartdisease/.

5. Uebing A, Steer PJ, Yentis M, Gatzoulis MA. Pregnancy and congenital heart disease. BMJ. 2006.

6. Douglas PZ, Braunwald E. Braunwald's heart disease: a textbook of cardiovascular medicine. WB Saunders; 2005.
7. Elkayam U, Bitar F. Valvular heart disease and pregnancy part I: native valves. J Am Coll Cardiol. 2005;46(2):223-30.

8. Silversides CK, Colman JM, Sermer M, Siu SC. Cardiac risk in pregnant women with rheumatic mitral stenosis. Am J Cardiol. 2003;91(11):1382-5.

9. Bhatla N, Lal S, Behera G, Kriplani A, Mittal S, Agarwal N, Talwar KK. Cardiac disease in pregnancy. Int J Gynecol Obstet. 2003;82(2):153-9.

10. Hameed A, Karaalp IS, Tummala PP, Wani OR, Canetti M, Akhter MW et al. The effect of valvular heart disease on maternal and fetal outcome of pregnancy. J Am Coll Cardiol. 2001;37(3):893-9.

11. Hemmings GT, Whalley DG, O'Connor PJ, Benjamin A, Dunn C. Invasive monitoring and anaesthetic management of a parturient with mitral stenosis. Canadian J Anaesth. 1987;34(2):182-5.

12. Clark SL, Phelan JP, Greenspoon J, Aldahl D, Horenstein J. Labor and delivery in the presence of mitral stenosis: central hemodynamic observations. Am J Obstet Gynecol. 1985;152(8):984-8.

13. Tsiaras S, Poppas A. Mitral valve disease in pregnancy: outcomes and management. Obstet Med. 2009;2(1):6-10.

14. Kotekar N, Nagalakshmi NV. A rare case of peripartum cardiomyopathy posted for caesarean section. Indian J Anaesth. 2007;51(1):6.

15. Vinitha S. Medical and Surgical Diagnostic Disorders in Pregnancy. Jaypee;2003.

16. Pulmonary Hypertension. Heart Disease and Pregnancy. [Online] http://www.heartdiseaseandpregnancy.com/phy_ph_ ms.html.

17. Pieper PG, Hoendermis ES. Pregnancy in women with pulmonary hypertension. Neth Heart J. 2011;19(12): 504-8.

18. Kaneko T, Aranki SF. Anticoagulation for prosthetic valves. Thrombosis. 2013;2013.

19. SM SC, Sermer M, Harrison DA, Grigoriadis E, Liu $\mathrm{G}$, Sorensen $\mathrm{S}$ et al. Risk and predictors for pregnancy-related complications in women with heart disease. Circulation. 1997;96(9):2789-94.

20. Khairy P, Ouyang DW, Fernandes SM, Lee-Parritz A, Economy KE, Landzberg MJ. Pregnancy outcomes in women with congenital heart disease. Circulation. 2006;113(4):517-24.

Cite this article as: Cicily TJ, Sams S, Alphonse SC. Pregnancy and heart disease: risk and predictors of obstetric complications. Int J Reprod Contracept Obstet Gynecol 2017;6:2191-7. 